\title{
CORRIGENDUM
}

\section{Real-time and in situ monitoring of mechanochemical milling reactions}

Tomislav Friščić, Ivan Halasz, Patrick J. Beldon, Ana M. Belenguer, Frank Adams, Simon A. J. Kimber, Veijo Honkimäki and Robert E. Dinnebier

Nature Chemistry 5, 66-73 (2013); published online 2 December 2012; corrected after print 8 January 2013.

In the version of this Article originally published, EPSRC and J. K. M. Sanders should have been included in the Acknowledgements section; this has now been corrected in the HTML and PDF versions of this Article. 